\title{
Additional Limit Conditions for Breakout Trading Strategies
}

\author{
Cristian PĂUNA \\ Economic Informatics Doctoral School \\ Bucharest Academy of Economic Studies \\ cristian.pauna@ie.ase.ro
}

One of the most popular trading methods used in financial markets is the Turtle strategy. Long time passed since the middle of 1983 when Richard Dennis and Bill Eckhardt disputed about whether great traders were born or made. To decide the matter, they recruited and trained some traders (the Turtles) and give them real accounts and a complete trading strategy to see which idea is right. That was a breakout trading strategy, meaning they bought when the price exceeded the maximum 20 or 50 days value, and sold when the price fell below the minimum of the same interval. Since then many changes have occurred in financial markets. Electronic trading was widespread released and financial trading has become accessible to everyone. Algorithmic trading became the significant part of the trading decision systems and highfrequency trading pushed the volatility of the financial markets to new and incredible limits nowadays. The orders are built and sent almost instantly by smart computers using advanced mathematical algorithms. With all these changes there are many questions today regarding the breakouts strategies. Are the Turtle rules still functional? How can the Turtle strategy be automated for algorithmic trading? Are the results comparable with other modern trading strategies? After a short display of the history and the system's rules, this paper will find some answers to all these questions. We will reveal a method to automate a breakout strategy. More different trading strategies originating from the Turtle rules will be presented. A mathematical model to build the trading signals will be described in order to automate the trading process. It was found that all of these rules have a positive expectancy when they are combined with modern limit conditions. The paper will also include trading results obtained with the methods presented in order to compare and to analyze this capital investment methodology adapted especially for algorithmic trading.

Keywords: Financial markets, Breakout strategy, Turtle strategy, trading signals, algorithmic trading, high-frequency trading, automated trading systems.

1 Introduction

In the middle of 1983 , the most famous commodities trader at that time, Richard Dennis was disputing an interesting idea with his partner and friend Bill Eckhardt. The subject was about whether a good trader is born or made by education and training. The issue is still interesting today, even the answer was given a long time ago. "Richard believed that he could teach people to become great traders. Bill thought that genetics and aptitude were the determining factors" [1].

To decide the matter, they took large advertising announcements in Barron's, Wall Street Journal and New York Times. "Over 1,000 people had applied and only 40 applicants had been granted for an audience with Denis. Only 13 ultimately were chosen, with another 10 selected for a follow-on program the next year" [2]. The first group of traders was trained for two weeks at the end of December 1983. After the training, they received real money accounts funded with capital between 500,000\$ and 2,000,000\$ somewhere in February 1984 in order to apply the trading strategy for which they were trained. The students were called "the Turtles": "we are going to grow traders just like they grow turtles in Singapore" [3] said Richard Dennis to someone after he just returned from Asia.

The Turtle experiment remains maybe the most famous experiment in financial trading history until now. It was proved that trading abilities can be learned. Richard Dennis proved that with a complete trading system, 
defined by a simple set of rules, "people with little or no trading experience" [1] can become excellent traders. Due to the facts, the Turtle experiment is important also because he revealed and proved that the Turtle strategy used in trading is consistent and a reliable one. Many changes have occurred in financial trading in the last decades. Electronic trading was widespread released. "Electronic trading (ET) is the method that use information technology to bring together buyers and sellers in a virtual market place using an electronic trading platform and a network that links all participants" [4]. Using ET, financial trading has become accessible to everyone. An impressive number of private or institutional investors or trades is participating in markets every day with a single purpose: the profit. In the trading decisions process, algorithmic trading became a significant part of any informational system.

Today, the orders are built and sent almost instantly by smart computers using advanced mathematical algorithms. The high-frequency trading pushed the volatility of the financial markets to new and incredible limits nowadays on markets where "there is an exponential over-reaction to an action" [5]. With all these changes there are many questions regarding the Turtle strategy today. First of all, we are asking if the Turtle rules still functional in the new market conditions. It was found that there are several trading strategies deriving from the original Turtle system with positive profit expectancy that can be used with good returns in algorithmic trading (AT). In this paper, it will be presented a way to automate these models for automated trading systems (ATS).

A mathematical model to build the trading signals will be described in order to automate the trading process based on the presented strategies. It was found that all of these trading strategies have positive profit expectancy. The paper will also include trading results obtained with the methods presented in order to compare and to analyze this trading methodology adapted especially for algorithmic trading.

\section{The Turtle Strategy}

Starting from the Curtis Faith disclosures, an original Turtle member that decide to make public the Turtle trading system rules in order to stop the scams and commercial activities with this kind of information, the original Turtle strategy rules are about to describe all aspects regarding the markets traded, the position sizing, the entry rules, the stop loss conditions, the exits and the tactics when it is about large liquidity. All these rules can be found widely on [1]. In this section, we will present them on short, as based for the trading strategies that will be presented in the next chapter.

Regarding the market traded, the original turtle system was trading futures contracts of the most liquid US markets: 30 Years US Treasury Bonds, 10 Years US Treasury Note, Coffee, Cocoa, Sugar and Cotton commodities on New York Exchange, gold, Silver and Copper in Comex, Crude and Heating Oil and Unleaded Gas on New York Mercantile Exchange and Swiss Franc, Deutschmark, British Pound, French Franc, Japanese Yen, Canadian Dollar, S\&P 500 Stock Index, Eurodollar and 90 Day US Treasury Bill on Chicago Mercantile Exchange.

Regarding the position sizing, the turtle system uses a sizing algorithm depending on the US dollar volatility on the market. The concept is known today as "Market true Range" and it was at that time a very advanced methodology to establish the traded volume, especially to the fact that the electronic trading was not yet invented. The size was established as $1 \%$ of the trading capital divided by the market dollar volatility received as input data depending on the historical price movements form the last days. The method can be used even today in order to set the trading volume depending on the price volatility.

Regarding the entry rules, the turtle system has two strategies. Both were breakouts strategies, one on shorter-term based on a 20days breakout, the other for longer-term, based on a 50-day breakout. "A breakout is defined as the price exceeding the high or low 
of a particular number of days" [1]. For the shorter-term system, when the price exceeds the 20-days high, a buy order was initiated. If the price follows under the last 20 days minimum value, a short order is executed. For the longer-term entries, the 50 days minimum or maximum point was the decisive factor. The entry made by the above conditions regarding the 20 days extreme points it was ignored if the last breakout trade had resulted as a winning trade. He signals related with the 50 days maximum and minimum points were traded whether the previous breakout had been a winner or a losing trade.

The Turtle trading system has an adding position option. The initial entry is made on one unit according to the position size methodology. At half of the average range in price movement, the turtle system adds a position of one unit too. If the market continues to grow, after another half of the normalized average range another unit will be added, until the maximum four units accepted. The entries were initiated consistently, and this gave a positive expectancy just "because most of the profits in a given year might come from only two or three large winning trades" [1].

The stop-loss strategy involved by the Turtles was set up an automated stop at $2 \%$ of the account. In order to keep the total position risk at a minimum, if additional units were added, the stop for the earlier units was raised with $0.5 \%$ at the last entry point. All the opened positions have the same stop-loss defined by the last entry trade. An alternative stop loss strategy made with $0.5 \%$ risk was tested by Turtles system on different markets.

Regarding the exits, the Turtle system is a breakout system. It is known that most breakouts do not result in trends. Even so, closing the winning positions too early can cut significantly the profit expectation. The entries for the 20 days extreme points were closed when 10 days low or high occurs. The long positions were closed at the 10 days low price level; the sell positions were closed at the 10 days high price level. For the trades opened for longer periods, considering the 50 days breakout, the exits were made following the 20 days low and high. From the practice, these kinds of exits can erase the profit for a significant part of the trades and this is the main reason for the low expectancy of the Turtle system today. Another exit strategy must be found in order to improve the system in the new electronic trading environment and the new volatility conditions in today's markets.

The last element of the turtle system is regarding the tactics related to the market orders. The turtles usual placed limit orders instead of market orders because the limit orders offer a chance for better fills in nonelectronic market execution and less slippage than did the market orders. Today these can be made equally even it is about large volume traded. For the periods when the market runs fast with thousands of dollars per contract in minutes, the Turtles waited for a more stable market before to place their orders. Today the volatility is much higher than the 1984 year this specificity must be also improved in the trading system in order to have enough trades to count the profit at the end of a period.

As a conclusion the turtle strategy is a breakout trading system with a volume depending on the price volatility and exits depending on the price action. The system tries to catch longer trades using exits depending on the minimum price level for a period of time on the buy trades and the maximum given in a period for the short trades. It is expected today, due to higher volatility on the markets, the system to give us a lower profit. The fact is proved by the statistics. Even so, starting from the Turtle trading system some trading strategies can be developed and adapted for algorithmic trading to be used in the electronic trading environment today. Some of these trading strategies will be presented in the next chapter.

\section{Trading signals}

The AT in the ET environment represents the automation of trading decisions and orders. Computers using mathematical algorithms, based on the real-time price time series build the trading orders and send them with low- 
latency to the brokerage companies in order to be executed. Regardless of the algorithm used to build the trading decisions, in AT the trading signal is related with a Boolean variable which is true when a trade can be opened and false when no trade must be opened. Once the market was chosen and the trading volume computed by an exact methodology, the buy and sell orders will be generated depending on so-called signal variables. We note them here as a buy signal and sell signals. These variables will be calculated for each (i) time interval. For the Turtle system, the trading signals are given by:

$$
\left\{\begin{array}{l}
\text { BuySignal }_{i}=\left(p_{i}>\operatorname{Max}_{k=i}^{i-N} \operatorname{High}_{k}\right) \\
\text { SellSignal }_{i}=\left(p_{i}<\operatorname{Min}_{k=i}^{i-N} \operatorname{Low}_{k}\right)
\end{array}\right.
$$

where $N$ is the number of days considered for the turtle strategy ( 20 days for the shorter term strategy or 50 days for the longer term system), and High $h_{i}$ and Low $_{i}$ are the highest respectively the lowest value of the price level for each $i$ time interval in the $N$ number of days considered. For any market in ET the time price series give the values of $\mathrm{High}_{i}$ and $L_{\text {Low }}$ and the maximal and minimal valued of these series can be computed to find the values of the trading signals in real-time.

\subsection{Additional Limit Conditions}

Trading the signals given by (3.1) in the new market conditions can give us low results especially in those periods when the price is on overbought or oversold intervals. In these situations, the price can exceed the maximum of 20 or 50 days period and reversed strongly in the other direction after the signal is present and the trade is executed. The price movement in the reversed direction can be important and a high-frequency trading (HFT) strategy for AT can give a lot of losing trades. The overbought and the oversold intervals must be avoided in order to open new trades.

It was found that additional condition to avoid the extreme price will significantly improve the trading results and will increase the efficiency of the trading system. A proper mode to avoid these intervals is to use the "Price Cyclicality" function presented in [6]. Noting with $P C Y_{i}$ the price cyclicality function value for each $i$ time interval, the original Turtle trading conditions became:

$$
\left\{\begin{array}{l}
\text { BuySignal }_{i}=\left(p_{i}>\underset{k=i}{i-M} \operatorname{Migh}_{k}\right) \wedge\left(P C Y_{i}<\xi\right) \\
\text { SellSignal }_{i}=\left(p_{i}<\operatorname{Min}_{k=i}^{i-M} \operatorname{Low}_{k}\right) \wedge\left(P C Y_{i}>\varphi\right)
\end{array}\right.
$$

where $\xi$ and $\varphi$ are two functional parameters that can be optimized for each market in order to avoid opening orders into overbought and oversold intervals. In relation (3.2) it was changed the $\mathrm{N}$ interval with $\mathrm{M}$ specifically, in order to draw attention to the fact that the number of days $\mathrm{M}$ in AT and HFT can be different than the number of days $\mathrm{N}$ considered in the original Turtle system. It was found that the trading signals given by the relations (3.2) can generate reliable trades for different time interval than 20 respectively 50 days, considering the breakout for different time periods, depending on markets and the timeframe used.
More than that, it was found that trading for the small profit target, as is the case for HFT, the signals given by the relations (3.2) can be traded consistently, without to skip the signal if the last trade was a profitable trade, as in the original turtle system. The relations (3.2) can be traded each time when the conditions give us a true buy or sell signal. With a proper optimization for $\xi$ and $\varphi$, the M interval can be also considered a parameter specific to each market. And more than that, it was found that running the trading signals given by (3.2) can be also made with good results for different timeframe than the daily interval. The signals can also be optimized for four hours 
timeframe $(4 \mathrm{H})$ or for hourly timeframe if the trades are made in markets with strong liquidity and the target is small. Decreasing the time interval lower than $4 \mathrm{H}$ timeframe can imply a significant growth of the drawdown, but the $4 \mathrm{H}$ interval can give in some cases even better results than the daily interval for some markets. Trading results will be presented in the next chapter considering all these improvements.

The $P C Y$ function used to build the modified Turtle signals in (3.2) has also a functional parameter that can be optimized in order to improve the results. This parameter is the period considered to build the cyclicality function. More considerations about it can be found in the author source [6]. The signals (3.2) can be used for both AT and HFT.

\subsection{The Power of the Trend}

Trading the signals (3.2) will give us good results in most of the cases especially for HFT with a small profit target. However, there are cases when the signal can open a losing trade even for s very small profit target. These cases are related to the situations when the price exceeds the maximum level but the trend is not strong enough to continue the movement. A reversed price continuation will occur and the trade will generate a loss. A case like this is presented in Figure 3.1.

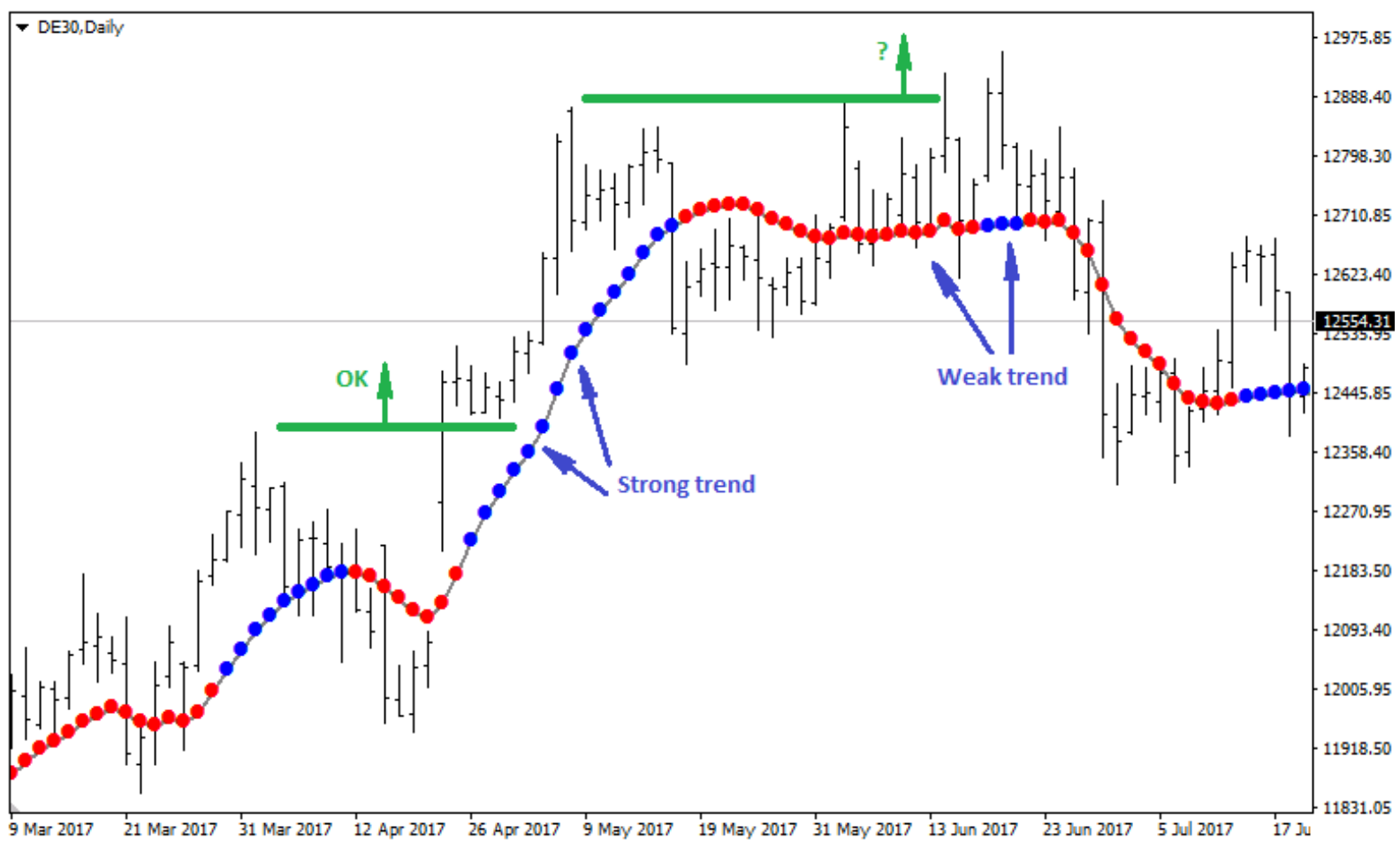

Fig. 3.1. Turtle signals on strong and weak trends.

As we can see in Figure 3.1, the first Turtle signal occurs in a strong trend and the trades were profitable. In the second situation, the trend was weak and the trades produced losses. Not the amplitude of the price movement can indicate if the price trend is strong or weak. It was found that can be found strong local price movements in a weak trend. It was found also statistically that a good Turtle signal can be also followed by another good and strong trend, the measure to skip the next signal if the last trade was profitable is not a productive measure in AT and HFT.

In Figure 3.1. it is presented the "Price Prediction Line" [7], which is a trend line built using a trigonometric interpolation. More details about how to compute the PPL together with code samples are presented in [8]. As it is presented in the author paper, the gradient of this line is a good indicator of the power of the trend. A high distance between two consecutive points of the price prediction 
(PP) line indicates a strong trend. A small difference between two consecutive points of the PP line will indicate a weak trend. This can give us the possibility to make additional limit conditions in order to filter the trading signals. With this filter, the trading signals will be:

$$
\left\{\begin{array}{l}
\text { BuySignal }_{i}=\left(p_{i}>\underset{k=i}{i-M} \text { Migh }_{k}\right) \wedge\left(P C Y_{i}<\xi\right) \wedge\left(P P_{i}-P P_{i-1}>\delta\right) \\
\text { SellSignal }_{i}=\left(p_{i}<\operatorname{Min}_{k=i}^{i-M} \text { Low }_{k}\right) \wedge\left(P C Y_{i}>\varphi\right) \wedge\left(P P_{i}-P P_{i-1}>\delta\right)
\end{array}\right.
$$

where $\delta$ is the minimum gradient of the PP line for the trend is considered strong enough in order to initiate a new trade. The measure of $\delta$ is a functional parameter that can be optimized for each market.

\subsection{Two days channel}

A particular form of the modified Turtle trading signals presented in subsection 3.1. is obtained for the case when the price makes a particular pattern. It was found that when the yesterday high did not exceed the previous day high and the yesterday low is higher the previous day low and the current price level exceeds the last two days high, the trading signals can give significant results. In these situations, the buy trading signal given by (3.3) can be rewritten as:

$$
\begin{aligned}
& \text { BuySignal }_{i}=\left(\text { High }_{i-1}<\text { High }_{i-2}\right) \wedge\left(\text { Low }_{i-1}>\text { Low }_{i-2}\right) \wedge \\
& \left(p_{i}>\text { High }_{i-2}\right) \wedge\left(P C Y_{i}<\xi\right) \wedge\left(P P_{i}-P P_{i-1}>\delta\right)
\end{aligned}
$$

It was found that the trading signals given by relation (3.4) can be also built with good results for $4 \mathrm{H}$ timeframe, not only for daily intervals. The sell signal can also be built similarly with (4) for those markets where short trades can be considered.

\subsection{Three days channel}

It was found that extending the (3.4) relation for an interval of three days we can obtain a significant return. For this case the trading signal can be automatically built with the formula:

$$
\begin{aligned}
& \text { BuySignal }_{i}=\left(\text { High }_{i-1}<\text { High }_{i-3}\right) \wedge\left(\text { High }_{i-2}<\text { High }_{i-3}\right) \wedge \\
& \left(\text { Low }_{i-1}>\text { Low }_{i-3}\right) \wedge\left(\text { Low }_{i-2}>\text { Low }_{i-3}\right) \wedge\left(p_{i}>H i g h_{i-3}\right) \wedge \\
& \left(P C Y_{i}<\xi\right) \wedge\left(P P_{i}-P P_{i-1}>\delta\right)
\end{aligned}
$$

The parameters $\xi$ and $\delta$ can be also optimized for good results using daily and four hours timeframes. The formula (3.5) can be also extended for more days intervals, but this case is not so numerous.

\subsection{The limit of the price}

The relations (3.3), (3.4) and (3.5) can be used with good results for AT and HFT. For HFT where the profit target is close, the signals can generate a significantly high number of trades. For HFT an additional condition must be imposed in order to avoid opening trades on a much higher price level. It was found that using a limit condition for the price not to exceed a specified distance from the PP is a good and functional solution. With the additional condition, the HFT signals can be adapted starting from the previous signals as:

$$
\text { BuySignal }_{H F T i}=\text { BuySignal }_{i} \wedge\left(p_{i}<P P_{i}+\lambda\right)
$$


where $\lambda$ is a functional parameter that can be optimized for each traded market. For HFT the parameter $\lambda$ will permit to automate the process of waiting for a better price level in order to make the next trade in HFT. Because the target in HFT is small, the $\lambda$ parameter will assure that the price is close enough to the PP line in order to complete the target until the next new local maximum point. Trading results with all these signals will be presented below. For HFT the buy signals (3.6) can also be compbined with the Fisher function limit conditions. Additional information about computational models and trading signals using Fisher function for AT and HFT can be found in [9].

\section{Trading results}

In this section, we will see trading results obtained with the signals presented above. These results were obtained using TheDaxTrader [10], an automated trading system that uses modified Turtle trading signals in order to generate buy trades for Frankfurt Stock Exchange Deutscher Aktienindex DAX30 [11].

Table 1. Trading results of different breakout strategies with additional limit conditions

\begin{tabular}{|c|c|c|c|c|}
\hline $\begin{array}{c}\text { Trading signal } \\
\text { and timeframe }\end{array}$ & $\begin{array}{c}\text { Number } \\
\text { of trades }\end{array}$ & Profit & Drawdown & $\begin{array}{c}\text { Risk to } \\
\text { reward ratio }\end{array}$ \\
\hline $\mathbf{( 3 . 4 ) + ( 3 . 6 )}$ M=2 D1 & 132 & 19,574 & 3,687 & $1: 5.31$ \\
\hline $\mathbf{( 3 . 5 ) + ( 3 . 6 )}$ M=3 D1 & 7 & 1,061 & 388 & $1: 2.73$ \\
\hline $\mathbf{( 3 . 3 ) + ( 3 . 6 )}$ M=5 D1 & 64 & 9,269 & 2,890 & $1: 3.21$ \\
\hline $\mathbf{( 3 . 3 ) + ( 3 . 6 )}$ M=10 H4 & 67 & 9,764 & 2,888 & $1: 3.38$ \\
\hline $\begin{array}{c}\text { All above signals to- } \\
\text { gether }\end{array}$ & 150 & 22,302 & 3,693 & $1: 6.03$ \\
\hline
\end{tabular}

For all modified Turtle signal presented, good optimization for the parameter set can assure a positive income with a reasonable risk to reward ratio (RRR). The lowest capital exposure is obtained for the signals made with (3.5)
The results presented in table 1 . were obtained for HFT of DAX30 the period 01.06.2015 30.06 .2018 using a fixed target of 10 points for each trade. The DAX30 index market was traded as a contract for differences (CFD) with a spread of 1 point. The exposed capital involved and the risk management were made using the "Global Slot Loss Method" [12].

The modified Turtle trading signals were built for daily and four hours timeframe interval. An additional condition was imposed regarding the hourly intervals of the executed trades between 8:00 and 16:00 coordinated universal time (UTC) in order to ensure the liquidity on the market. In table 1 . are presented the trading results for cyclicality limit $\xi=99.9$, power of the price trend $\delta=5$ and the limit price $\lambda=10$. The trading signals (3.3) were optimized for $M=5$ in the daily timeframe and for $M=10$ in the $\mathrm{H} 4$ timeframe. The signals were repeated one time in four hours. For the trading signals (3.4) and (3.5) the signals were repeated one time per one minute. In all trading process, only one opened trade was accepted at a time. and (3.6). The best individual RRR was obtained using (3.4) and (3.6) but all signals traded together produced a RRR of 1:6.03 in a period of 30 months. The capital evolution in this interval trading all modified Turtle signals with HFT is presented in Figure 4.1. 


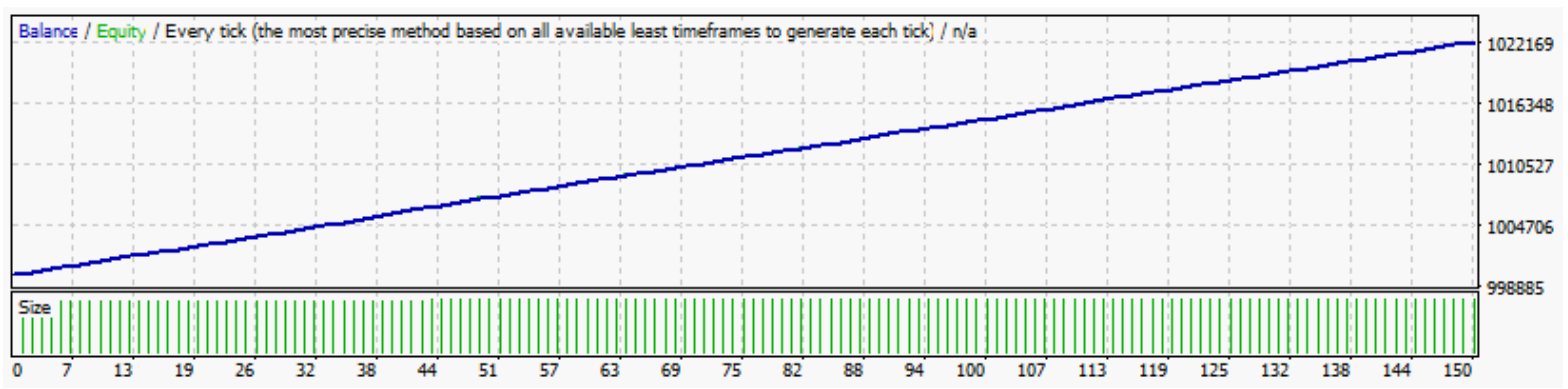

Fig. 4.1. Capital evolution due to the trades made by modified Turtle signals

\section{Conclusions}

The breakout turtle trading system can be adapted for AT and HFT in ET for today's markets.

The first improvement must be made in order to avoid the overbought and oversold price intervals. For this purpose, we used the price cyclicality function [6]. The second improvement must be made in order to avoid opening trade in weak price trends. For this second purpose, we used the price prediction line [7] in order to measure the trend power and to limit the trading signal.

With all these conditions, the modified Turtle trading signal can produce a significant number of trades with positive profit expectancy. The new trading methodology can be optimized based on some functional parameters in order to be traded on different timeframe intervals. A different number of days can be used than the original Turtle system, in order to increase the number of trades and to grow the trading efficiency.

The modified Turtle trading signals were traded for 5 days interval and 10 intervals of $\mathrm{H} 4$ with good returns. A particular form of the modified Turtle signals was found using two days interval when yesterday high and low are lower respectively higher than the days before high and low. This particular trading signal generated the highest number of trades with a RRR of 1:5.03. All presented trading signals traded together generated a RRR of 1:6.03. Starting these results it can be said that the modified Turtle trading signals are reliable for AT and HFT.

The optimization process of the functional parameters of the trading signals presented can be made using a time price series of the historical price for any market with good liquidity. These signals can be also optimized for AT with longer profit target for automated trading or investment systems.

\section{References}

[1] C. M. Faith, 'The Original Turtle Trading Rules. Fighting the Scams, Frauds and Charlatans', 2003. Available at: http://originalturtles.org/turtlerules.pdf

[2] C. M. Faith, 'Way of the Turtle. The Secret Methods that Turned Ordinary People into legendary Traders', McGraw-Hill, 2007 ISBN: 978-0-07-148664-4, pp. XX

[3] S. W. Angrist, Wall Street Journal, 09.05.1989

[4] C. Păuna, 'Automated Trading Software. Design and Integration in Business Intelligence Systems', Database System Journal, Volume 1, 2018. ISSN: 2069-3230

[5] E. Peters, 'Chaos and Order in Capital Markets. A New View of Cycles, Prices and Market Volatility', 1996, John Wiley \& Sons Inc., ISBN 0-471-13938-6

[6] C. Păuna, I. Lungu, (2018), Price Cyclicality Model for Financial Markets. Reliable Limit Conditions for Algorithmic Trading, Economic Computation and Economic Cybernetics Studies and Research, Vol. 52, Issue 4/2018, ISSN: 1843-0112. DOI: 10.24818/18423264/52.4.18.10

[7] C. Păuna, (2018), Trend Detection with Trigonometric Interpolation for Algorithmic Trading, under final review at Scientific Annals of economics and Business, ISSN: 2501-3165

[8] C. Păuna, (2019). A Prediction Model Using The Price Cyclicality Function Optimized for Algorithmic Trading in financial Market, Athens, Greece: world Academy Of Science, Engineering and 
Technology. Proceeding of International Conference on Intelligent Information Systems ICIIS 2019. Available at https://waset.org

[9] C. Păuna, (2018). Reliable Signals Based on Fisher Transform for algorithmic Trading. Timișoara, Romania: Timisoara Journal of Economic and Business, Vol. 11, Issue 1:2018. ISSN: 2286-0991. West University of Timişoara. DOI: $10.2478 / \mathrm{tjeb}-$ 2018-0006 Available at: https://tjeb.ro

[10] C. Păuna, TheDaxTrader. Automated trading system, 2010. Online software presentation. Available at: https://pauna.biz/thedaxtrader

[11] Börse, Frankfurt Stock Exchange Deutsche Aktienindex DAX30 Components, 2018. Available at: http://www.boerse-frankfurt.de/index/dax

[12] C. Păuna, Capital and Risk Management for Automated Trading Systems, Iași, Romania: Proceedings of the 17th International Conference on Informatics in Economy, 2018, pp 183-188. Alexandru Ioan Cuza University. Available at: https://pauna.biz/ideas

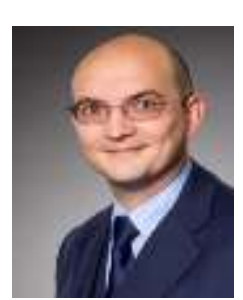

Cristian PĂUNA graduated the Faculty of Cybernetics, Statistics and Economic Informatics of the Bucharest Academy of Economic Studies in 1999 and he is also a graduate of the Aircraft Faculty from the Bucharest Polytechnic University in 1995. He got the title of Master of Science in Special Aerospace Engineering in 1996. In the last decades, he had a sustained activity in the software development industry, especially applied in the financial investment domain. Based on several original mathematical algorithms, he is the author of several automated trading software for capital markets. At present, he is the Research and Development Manager of Algorithm Invest company and he is involved as a $\mathrm{Ph} . \mathrm{D}$. student in the Economic Informatics Doctoral School of the Bucharest Academy of Economic Studies. 